\title{
ROBOTS AND AR: TOWARDS A PLATFORM ECONOMY FOR CONSTRUCTION
}

\author{
SPECIAL ISSUE: Virtual, Augmented and Mixed: New Realities in Construction
}

PUBLISHED: December 2019 at https://www.itcon.org/2019/29

EDITORS: McMeel D. \& Gonzalez V. A.

DOI: $10.36680 /$ j.itcon.2019.029

\author{
Dermott McMeel \\ School of Architecture and Planning, Faculty of Creative Arts and Industries \\ d.mcmeel@auckland.ac.nz.
}

SUMMARY: Platform economies like Uber and AirBnB have emerged quickly to dominate and radically reconfiguring social, geographic and organisational structures of existing economic systems; putting markets into a state of contingency and flux. What is a platform economy for construction? This paper reports on research investigating the implementation and combination of new technology, made possible by through a 'platform' approach to disrupt design and making processes and offer insight into potential futures. This project explores automated robotic construction, automatic recognition of building components and Augmented Reality overlay of additional data. The paper reviews existing literature to explore similarities and differences between construction and other sectors being disrupted by platforms. The research methodology develops a digital software platform to investigate how much of the design, fabrication and assembly of a 'digital igloo'can be automated. The igloo itself is a simple structural form intended to showcase composite panels. Results reveal construction is organizationally strikingly similar to sectors currently being disrupted. They also show the surprising extent to which design, fabrication and assembly can be contained within a digital platform. The biggest challenge was perhaps to do with tolerance, specifically when and where there is a focus on precision. Conclusions suggest the complexity of construction is likely to prevent an immediate and complete shift to a platform economy. It is more likely in the short term that contained and discrete aspects of construction, such as transport or equipment, might be suited to adoption.

KEYWORDS: Hololens, Augmented Reality, Digital Fabrication, Design, Data, Visualization

REFERENCE: Dermott McMeel (2019). Robots and AR: towards a platform economy for construction. Journal of Information Technology in Construction (ITcon), Special issue: 'Virtual, Augmented and Mixed: New Realities in Construction', Vol. 24, pg. 527-539, DOI: 10.36680/j.itcon.2019.029

COPYRIGHT: (C) 2019 The author(s). This is an open access article distributed under the terms of the Creative Commons Attribution 4.0 International (https://creativecommons.org/licenses/by/4.0/), which permits unrestricted use, distribution, and reproduction in any medium, provided the original work is properly cited.

\section{(c) creative}




\section{INTRODUCTION}

The $21_{\text {st }}$ Century has been dominated to date by the emergence of 'platform economies' like Uber and AirBnB. They are defined by the development of a digital platform that becomes central to the exchange of things between services providers and service users. A feature of these companies is their use of digital platforms (bit and bytes) to reorganize or connect physical assets (atoms and molecules). This is a departure from earlier platforms which centered on the digitization and exchange of things, such as music, videos or personal data. This shift has seen digital economies emerge and come to dominate sectors - such as room rentals and taxis-that would have historically been considered insulated from digital platforms as the value they provide involves things (cars, rooms) that cannot be digitized.

Construction is arguably one such sector, I will make the case for this point in greater detail later in this section. This presents a cause for concern as Uber and AirBnB entered and dramatically disrupted established sectors to which they were new. Incumbent stakeholders did not have a response to these startups; this type of disruption does not favor existing constituents of a sector. It provides greater convenience for the service users but it is often associated with greater uncertainly for the providers (Glöss, McGregor and Brown, 2016). It redistributes wealth, power and the platform — and thus algorithms - become the main mediator of the service, not people.

A defining feature of both the taxi and rental/accommodation sectors is that there are a small number of large intermediary companies that connect the actual provider (the taxi driver or rental provider) to the service user. The intermediaries do not provide much of the core service, which is similar to most multinational construction companies. In most cases main contractors are only responsible for between $10 \%$ and $20 \%$ of the actual construction work (Hinze and Tracey, 1994; Kumaraswamy and Matthews, 2000). The vast majority of the core service - the building work - is undertaken by a large under of independent sub-contractors; a structure which is mirrored to a significant degree in the taxi and rental sector. This is the central reason, we believe the construction sector urgently needs research into possible uses for digital platforms.

In this paper we outline research focused on the creation of a platform that facilitates the design of an 'igloo' to be assembled from composite panels. By digitizing and automating many intermediate processes the research explores what value is created and what innovations become possible, having access to this data across multiple systems.

Using data to help shape the built environment is not a new phenomenon, the use of environmental information to inform building decisions can be found in Vitruvius' 'The Ten Books of Architecture' in the first century BC (Pollio and Morgan, 1960; McEwen, 2003). However, we currently find ourselves in a maelstrom of data, thanks to the Internet of Things (IoT) and the proliferation of digital infrastructure and connected devices. Virtually everything we do on mobile devices can be tied to a place and time. A google search will reveal dozens of city 'dashboards,' which store and stream data from sensors deployed across the world. If we consider data and its connectedness a utility, like many new utilities, it is initially ad-hoc with different often uncoordinated providers (Graham, 2002) and the infrastructure that sits behind it is thus contested. Some initiatives are driven from the top-down, funded by multinational corporations focused on monetizing the infrastructure (Romm, 2015). Others are bottom-up community initiatives like The Thing Networks, creating community sponsored infrastructure. In different ways both are interested in the creation of new value through data, something that Speed and Oberlander are interrogating through Design Informatics (Speed and Oberlander, 2016). Although there is a history of using information to inform decision making in regard to the built environment, I suggest we are entering a profoundly different epoch. One where the quantity, quality and granularity of information available on the built environment is unprecedented in human history. The challenge is not necessarily finding data, it is the creation, encoding and reproduction (or visualization) of data at a time and place which is meaningful and useful. The construction process has, historically, been resistant to innovation and new technology, and it is reported that approximately $80 \%$ of technology implementations and innovations do not persist beyond trials within the construction environment (Peansupap and Walker, 2005). It is suggested this is because the construction environment is - partially at least - highly dynamic if not chaotic (McMeel and Coyne, 2004; McMeel, Coyne and Lee, 2005). It is contingent on weather and is necessarily dirty and dusty, all of which are highly problematic for digital technology. 
However, the use of technology and data in architecture and construction is not a new challenge or innovation. It can be traced back to the 1400's when the Architect and Artist Alberti was pioneering numeric encoding of graphical information (Carpo, 2011, p. 54). Alberti was primarily attempting to facilitate the reproduction of his complex and detailed map of Rome, the 'Discriptio Urbis Romae' (Carpo et al., 2007). Alberti realized there was value in enabling and allowing the sharing of his map. Thus, he created a device and a numerical annotation system that would allow anyone to accurately locate key locations within Rome on a surface. This would make it considerably easier to accurately locate points and create an accurate scaled visualization that was geometrically superior to anything currently in existence. Returning to the subject of this paper what we have in Vitruvius and Alberti is part of a historical continuum that recognizes the value of data as well as the development of technology and machines for its encoding and sharing.

\subsection{Augmented Reality}

Augmented Reality (AR) is the projection of an image onto some form of wearable glasses, which enables the wearer to have a layer of digital information presented overlaid onto whatever they are viewing through the glasses. It is part of this continuum of innovation and presents new possibilities for sharing, reproducing and visualizing data. There have been regular attempts to create 'digital' hardhats for construction sites. These hats usually have a protective screen to protect the eyes of the wearer, this screen doubles as a surface for AR projections. Such devices remain rare on construction sites, in fact digital innovations specifically for deployment on construction sites are rarely successful (Peansupap and Walker, 2005). Elsewhere research speculates this is due to the rugged nature of construction sites; dust, dirt and moisture make is a harsh environment for digital devices (McMeel, 2009). However, AR research has explored many sectors; it has been applied to training for harsh or dangerous environments (Wang and Dunston, 2007); used investigated use-cases using AR to assist the positioning of electrical fitting in building interiors (Chalhoub and Ayer, 2018); augment construction drawings through an iPad as well as to navigate virtual spaces (Amor et al., 2012; McMeel and Amor, 2013). Despite it being a burgeoning field of research actual implementation on construction projects remains rare.

Moving for a moment to consider AR conceptually and ideologically, data and the infrastructures through which it flows has come under scrutiny from various geographers, economists and theorists that claim it influences our decision-making (Schön, 1979; Massey, 1994; Thrift, 2005). The challenge becomes how to use it in a meaningful way. Buildings, during their construction and operational lifecycle generate copious amounts of data (Burry, Burry and Davis, 2011). Although the software systems are often closed which significantly limits data sharing and innovation (McMeel and Amor, 2012).

\subsection{Robotics}

Turning our attention to robotics for assembly, the automation of making is not a new phenomenon. The Industrial Revolution marked the beginning of machines supplanting people in the crafting of things (Hale, 1994). Computer numerical controlled (CNC) routers were invented in the 1940s and 1950s and robotic arms were developed by NASA in the 1960s. As ease of use has increased they have found their way into many industries. The last decade has seen various centers and organizations emerge focusing on robotics in architecture or construction (Bock and Linner, 2009; Menges, 2012; Braumann and Brell-Cokan, 2013). One feature of all research involving the common linear kinematic robot is its need to be fixed in place. Or at the very least fixed to a computer controlled rail. This limits the scale of things that can be made or assembled robotically. The research project discussed in this paper explores a method of enabling the free movement of a robot within a working environment thus dramatically increasing the scale of possible construction possibilities.

The research covered in the following sections documents the robotically assisted construction of an 'igloo' structure from composite panels. The project is a collaboration between the Centre for Advanced Composite Material and the Faculty of Creative Arts and Industry, both located within the University of Auckland in New Zealand. During the construction process we want to visualize structural data onto the real-world composite components before they are fixed in place. The aim of the research is to investigate techniques for using and visualizing data in complex assembly processes. 


\section{BACKGROUND}

The construction industry has a checkered past with regards to productivity. When compared to improvements in the manufacturing and finance sectors, construction appears relativity unchanged in the past 30 years (Ruddock, 2006; Bock and Linner, 2009; McMeel, 2009). There have been various attempts to address this, in the UK alone two major reports influenced revisions to construction procurement practice in 1990's (Latham, 1994; Egan, 1998). The results were mixed, some selective implementation of the recommendations did solve a number of preexisting problems. However, the changes to procurement most notably the introduction of PPP (Public Private Partnerships), created new problems with quality and lifecycle maintenance (Bresnen and Marshall, 2000; Hill, 2001). Currently the UK has established the BIM Task Group, aimed at implementing BIM, in an attempt to again improve the design and construction process.

Construction continues to come under criticism, in particular because it generates a remarkable amount of waste (Bossink and Brouwers, 1996). It also causes significant disruption particularly when construction is in an urban or suburban area. This is particularly relevant in Auckland, New Zealand where a housing shortage and a new regulatory plan have dramatically increased construction in these areas. It is becoming apparent through academic studies and reports in the popular press that traditional construction logistics and timeframes have a significant impact on surrounding residents quality of life (Barton, 2014; Gordon, 2015; Priestley, 2015). Increasingly, construction is not on 'green field' sites, it is in urban or suburban environment. As such there continues to be a need to identify ways in which construction can evolve into a faster more efficient process.

There have, of course, been innovations and improvements to building construction. There has been steady progress in methodologies for off-site construction such as panelized and volumetric approaches to building. Cladding systems have widely adopted a panelized approach, although much commercial construction remains an on-site activity. The evolution of prefabrication - now widely accepted — was not without early implementation problems. Initially it suffered from quality issues and occasional structural failures (Pearson and Delatte, 2005) and by the 1980's it was becoming synonymous with socio-economic problems (McLeod, 1983). Currently offsite construction is much more reliable and associated with quality; it is the core of companies like Lindbacks and HUF-haus. These companies' on-site activities are best described as 'assembly' rather than 'construction,' which is faster and produces less waste. Other prefabrication companies such as FACIT Homes take a different approach by moving shipping containers onto site, fitted internally with a computer numerical controlled (CNC) router. On site bespoke plywood boxes are manufactured, which interlock becoming the primary structure of the building; it is analogous to the process of assembling Lego. However, because the construction sector is largely made up of small to medium sized enterprises (SME's), much building work remains traditional. The investment needed to facilitate the transition to modern methods of construction such as prefabrication mean it is out of reach for approximately $90 \%$ of the construction sector that is comprised of SME's (McMeel and Sweet, 2016).

Currently automated construction is only one of a series of ongoing initiatives intended to produce productivity and quality improvements in the construction sector. Most developed nations also have BIM (Building Information Modelling) initiatives as well as working groups researching Lean Construction and Integrated Design and Delivery (IDD). This reflects the growing concern that construction is in need of dramatic change on many fronts. In order to find a meaningful way forward this research turns towards the marine composite material manufacturing sector. In many ways it is very similar to the construction sector; it builds big things, which are highly engineered and involve a lot of specialist collaboration. A key point of difference is that they are more advanced in their use of automated fabrication, testing and computer simulation. By looking at this sector we gain valuable insights into possible ways for the construction sector to evolve and what immediate research might produce results.

\subsection{The Composite sector: challenges and opportunities}

The composite manufacturing sector is currently facing challenges that are relevant to the construction industry. This provides a useful lens through which to look at construction; it also might point to areas of focus for research. Specifically, composite construction is like building construction in at least two ways. (1) It relies on individuals and their expertise, but test data can be difficult to access by these experts in a hands-on manufacturing/on-site environment. There is interest exploring how test data can be visualized and made available to experts during fabrication to assist their decision-making. (2) They are faced with the problem of how to use these sophisticated fabrication machines when the thing being fabricated-parts of a yacht (or building)-is bigger than the machine 
can make? In this project we were presented with the opportunity to investigate these two aspects.

\subsection{The research aims}

The research had two specific aims: (1) To create a technology demonstrator using general purpose manufacturing robots that could be moved around a construction process and continue to assemble an object from any location. Thus being able to assemble something much bigger than is possible with a fixed robot. (2) To visualize and reintroduce structural component data into this construction process. The project does not seek to address or report on any specific Health and Safety aspects of AR as these are well reported elsewhere (Wang and Dunston, 2007; Sulankivi et al., 2010).

\section{THE DIGITAL IGLOO PROJECT}

To address the two aims we undertook a research project to design and assemble a 'digital igloo' (Fig. 1). The project had four distinct parts (1) automated fabrication and robotic assembly of unique composite panels into an igloo structure (2) visual augmentation of individual composite panels with data obtained from specialized structural testing (3) implementation of a parametric design system for the automatic generation of panel CNC cutting files and robot instructions for assembly (4) visual tracking system to monitor robot location.

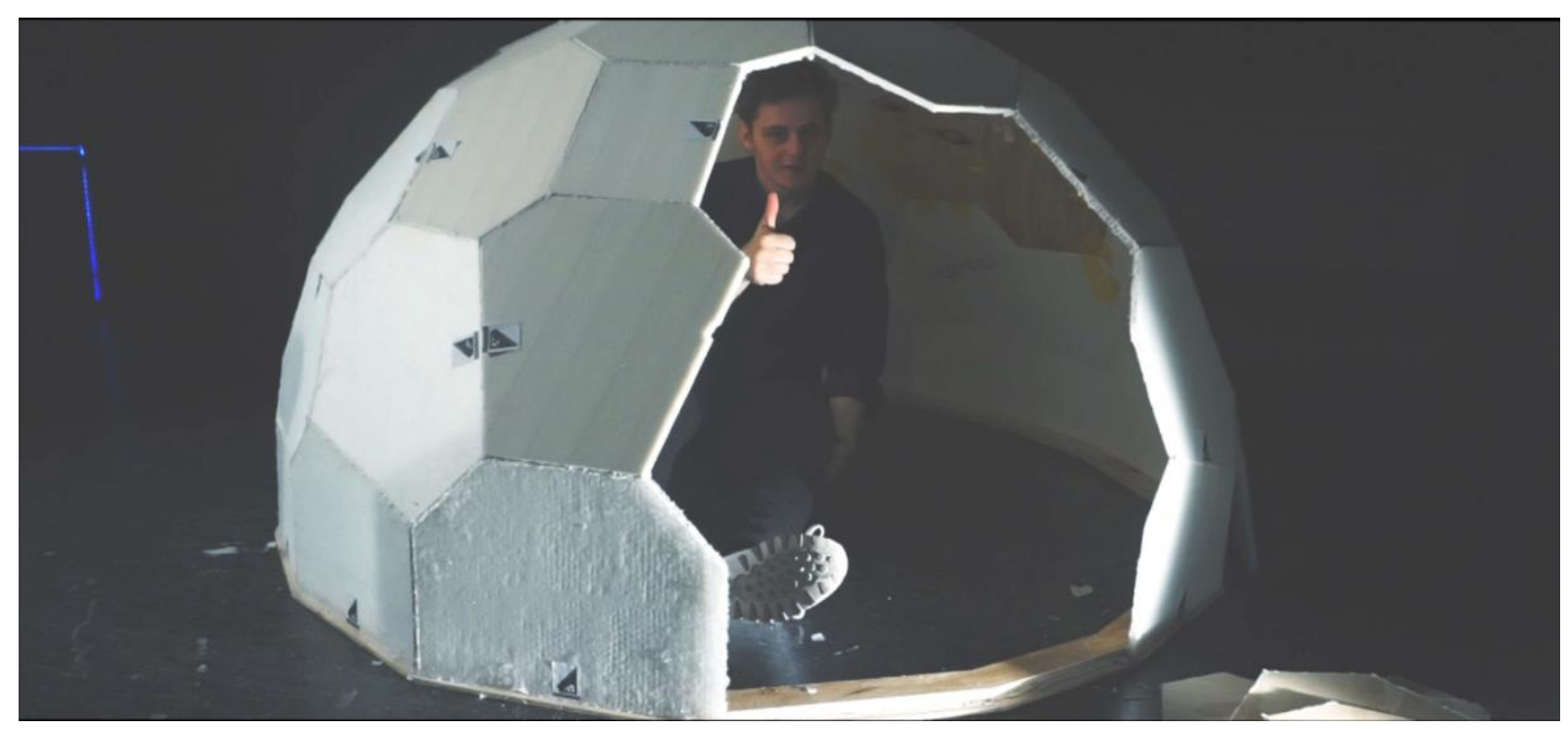

Fig. 1: The Digital Igloo.

\subsection{The research problems}

The research was addressing two problems that are common to composite manufacture and assembly but are also applicable to other industries including construction. First, composite manufacture continues to be largely a manual process. It relies heavily on individuals with expertise and knowledge of the process, which limits the industry from scaling their market and customer-base. A problem which we can see has been largely overcome by Uber and AirBnB where a digital platform has been implemented. There is significant interest in exploring how and where processes might be automated. Second, flaws within the inside of a composite panel cannot be seen but can be identified through various structural tests. If a machine or manual fabrication process has a fault this most often within the hidden interior layers of the composite panel and not visible to the naked eye.

To fully understand the structural data is must be viewed in parallel with the panel. This is necessary because anomalies in the data can result from a change in panel thickness or shape. Results can also be affected if a panel has a penetration designed into it or has another material inserted. The result of this is that assessing a panel and its numerical data is a highly specialized process. The data is not fully understood by the fabricator and vice-versa the panel construction is not fully understood by the Finite Element Analysis expert. In addition, these panels may 
need specialist equipment or be brought to a specialist location to obtain the structural data. All of which disrupts the manufacturing process, leaving expertise and data scattered across various disciplines, locations and formats. Some recent research has used affordable sensors in combination with innovate sonic testing techniques to gather data quickly and easily from panels in the assembly environment and visualize it on a laptop. This novel innovation solves some of the problems of gathering and visualizing data without major disruption of the manufacturing process. However, laptops are cumbersome, and the data remained abstracted in a simple 2D graphic environment. We hypothesize, if we use AR then we can combine a more sophisticated visualization of the data and the physical panel.

\subsection{The solution}

There are two parts to the solution. First a design platform was implemented that powered the automated fabrication and assembly pipeline. Second an AR component, using the Microsoft Hololens, overlaid data on the panels as they were being assembled. The HoloLens was chosen for several reasons: it is widely available; has a mature development kit; and is quick to learn. The Hololens is also wireless, this is critical within the research to maintain maximum mobility for users. Finally, it is hands free, worn like glasses or a headset and once turned on can be controlled with gestures. Thus, there is no need to touch the device to interact with it. This was desirable within a manufacturing environment where dirt and moisture are present and protective clothing including gloves need to be worn.

\section{EXECUTION AND ANALYSIS}

This section will first explain how the four individual parts of the project merged together into a three day robotically assisted build of a 'digital igloo' by two research assistants. It will then turn specifically to analyzing the digital platform developed.

\subsection{Execution}

The project was executed in an Optitrack suite, which is a room fitted with high definition cameras around the perimeter. The position of an object fitted with special markers can then be tracked within the space with submillimeter accuracy. This technology is most commonly usually used to motion-track people for special effect in movies. In this case we placed special markers on our general-purpose ABB IRB120 robot, thus enabling us to track its precise location within the room (Fig. 2).

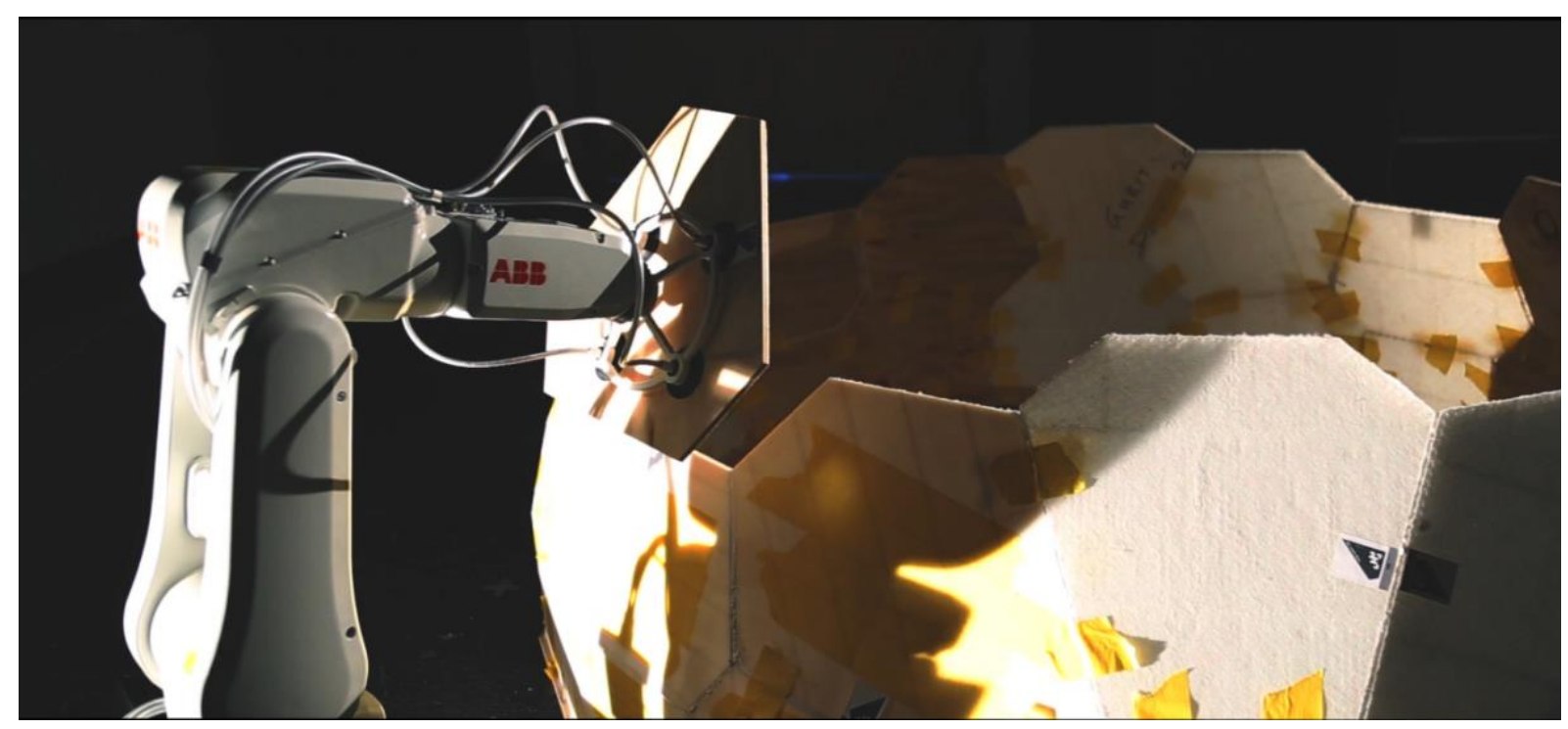

Fig. 2: Automated robotic assembly process. 
In parallel a sophisticated parametric design system was created using the Rhino 3D design software and the Grasshopper parametric software. This system was designed to:

1. Enable the design and modification of an igloo structure approximately 1.5 meters in diameter.

2. Automatically extrapolate and export individual panel geometry for cutting on a computer numerical controlled (CNC) router.

3. Automatically generate instructions to enable the robot to pick up and position a specific subset of panel in a specified sequence for assembly.

4. Automatically create undated instructions every time the robot was repositioned to enable easy and quick continued assembly from the new position.

The design platform was key to the successful execution of the project. Although the focus was automated assembly, there were important limits placed upon assembly by the robots used. For example, a panel's width and height had to be no less than $250 \mathrm{~mm}$ otherwise the suction cups on the robot end effector would not be able to pick it up. Similarly a panel's dimension could be no more than $500 \mathrm{~mm}$ in any given direction, as it would become too unwieldy to pickup and maneuver into place. The overall size of the igloo was limited by a combination of the maximum height the robot could reach approximately $600 \mathrm{~mm}$ and the dimensions of the door into the workshop $(1250 \mathrm{~mm})$. It was necessary to encode these limits into the design environments to avoid an igloo being designed that could not be assembled by the robots. In that event fabrication of panels might proceed unimpeded but during assembly the robots would stop at the problematic part of the process. The stopping of a production pipline in practice is incredibly expensive. Our aim was to create a process where the data in the digital platform was kept within key parameters to ensure the entire pipeline of processes (design, fabrication and assembly) could be executed consistently without errors or unexpected events occurring. Finally a special base was created for the robot with an integrated 'jig.' This was a feature to hold each panel is a precise and known position, critical to ensuring the system can pick up and position panels accurately.

With the robot in a given position, a researcher manually determined the number of panels that could be positioned from that specific location. These panels were programmed in order, positioned on the robots' jig sequentially and the instructions sent to the robot. From any one location the robot could position between two to four panels, then the robot was relocated. The new location was determined by the researchers using their expert knowledge of the process and what was or was not possible. The Optitrack position tracking technology combined with the parametric software system enabled automatic regeneration of the robot instruction set, which is what makes this innovation possible (Fig. 3).

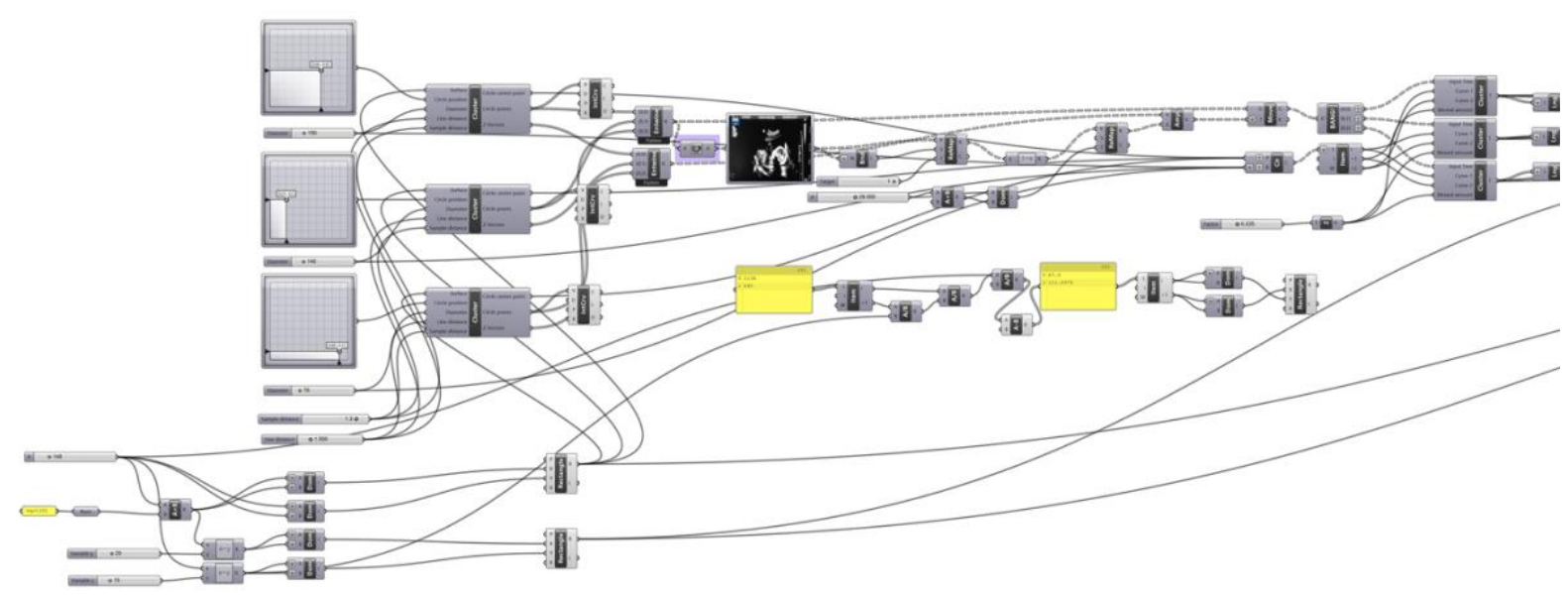

Fig. 3: Parametric design system, created in Grasshopper. 
The innovation here was enabling the ad-hoc and improvised repositioning of the robot. Traditionally robots are fixed in position and objects they interact with have their positioned accurately calibrated. This is an important process that is very time consuming. As a result, robots are rarely moved and their operations are thus limited to an area they can reach.

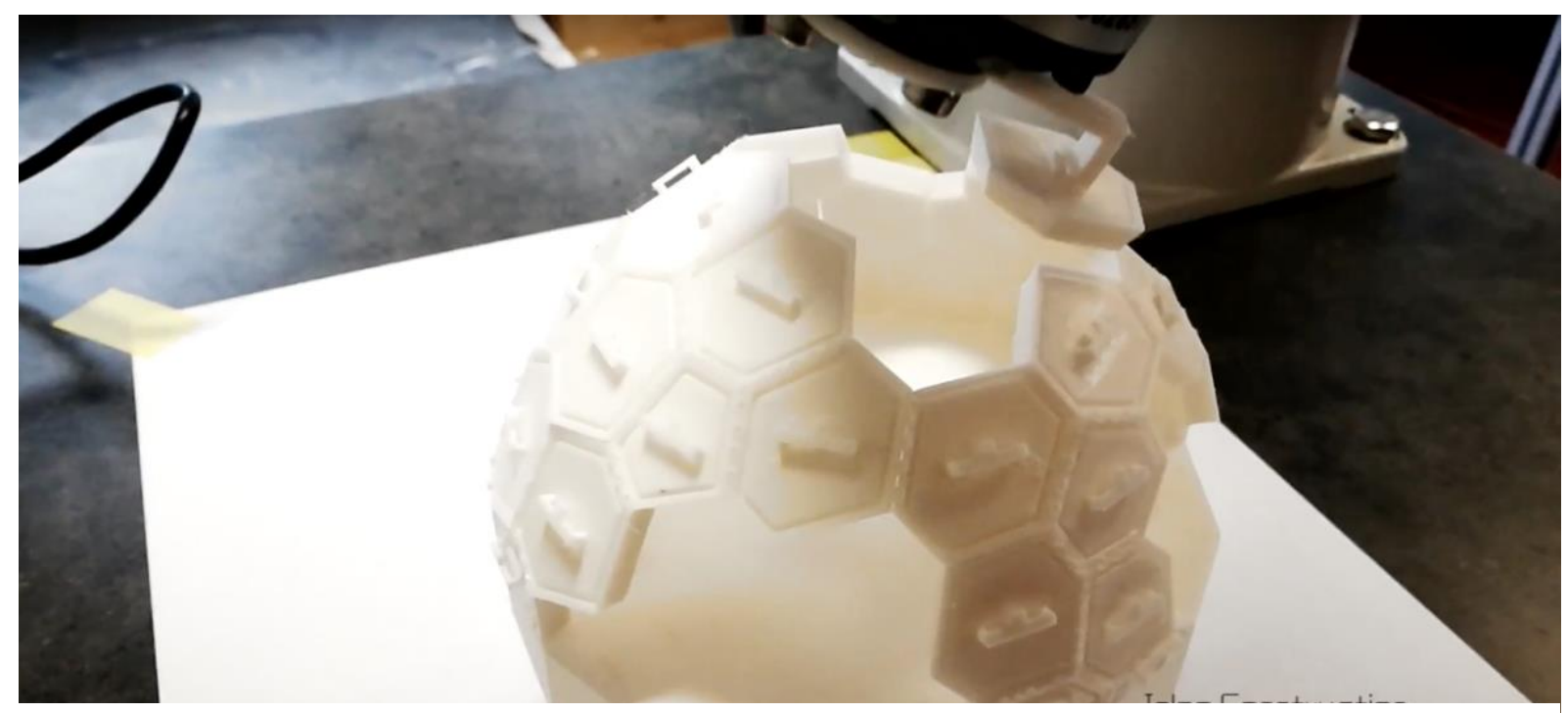

Fig. 4: Digital igloo, assembled from a fixed robot position. Image by Xi Shao

It is useful to compare this process with the previous phase of the research, which explored the igloo concept through the implementation of a parametric digital design platform with a fixed — not mobile — robot. In this case the maximum size of the igloo was limited by several factors including, how far the robot could reach, what mechanism was used to pick up the panels and where the robot was fixed in relation to the igloo. The same robot was used, an ABB IRB120 robot, and during the first phase of the research the maximum size of the igloo was $120 \mathrm{~mm}$ (Fig. 4). In this second phase of the research where the robot was mobile the diameter possible was $1200 \mathrm{~mm}$; an increase by a factor of 10 .

\subsection{Augmented Reality Implementation}

The AR concept for the project was first to implement a technique that would allow for the recognition of individual panels in the work space. Then to visualize the structural data for that panel within the Hololens and make it appear overlaid on the panel in the real world through the Hololens. Separate research at the Centre for Advanced Composite Materials was developing novel techniques for testing and gathering structural data from composite panels. The AR aspect of this research was to develop novel techniques for visualizing this data.

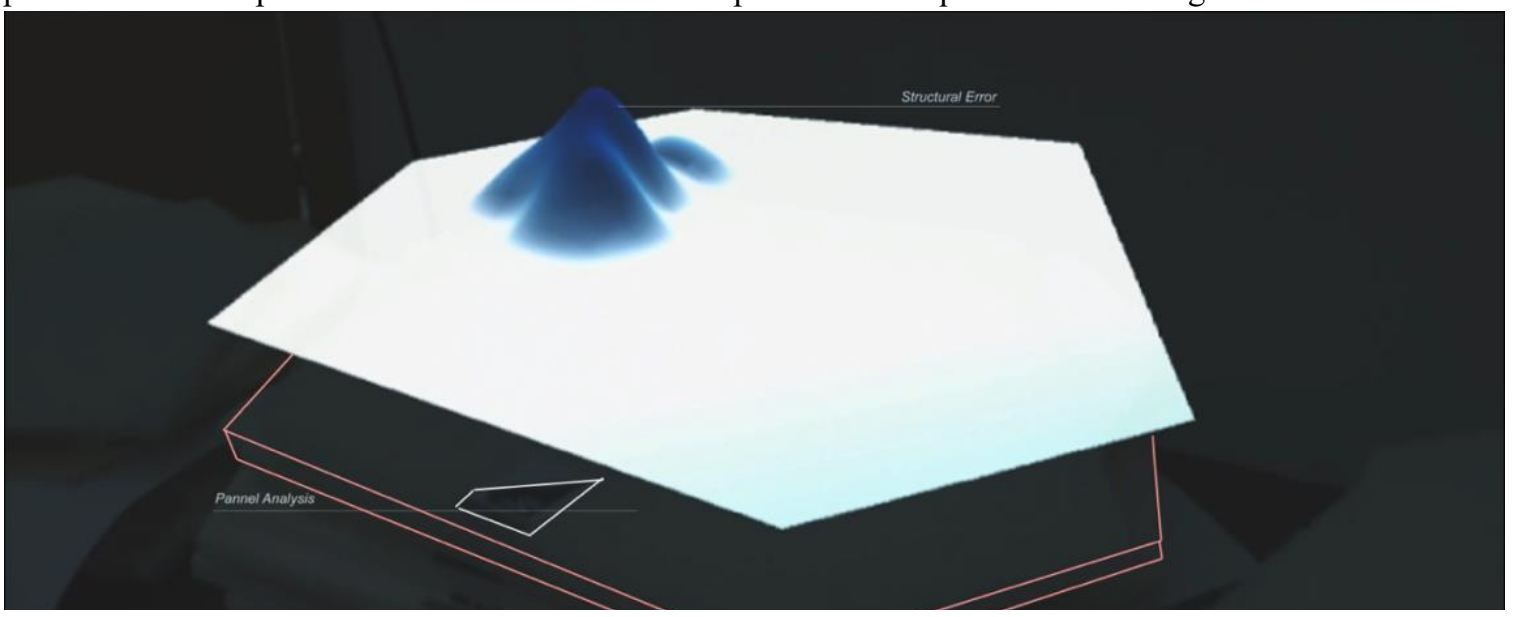

Fig. 5: AR environment with physical panel and overlaid data. 
To recognize the individual panel several vison systems were investigated, the most reliable system used unique markers fixed to each panel. To visualize the structural data two data sources had to be combined. Firstly, the shape of each panel had to be imported from the parametric design system. Then the structural data that was being gathered elsewhere was stored as a simple Comma Separated Variable (CSV) file. Our solution was to visualize a mesh surface created from these two pieces of data with the height of the surface at any given point representing a key piece of structural infomration. If this variable increases in value the height and color of the mesh changes (Fig. 5) to visually represent the data. In Fig. 5 the panel was constructed with a deliberate 'structural anomaly' which appears as a dramatically raised bump on the surface. This illustrates what the user would see if a faulty panel was present.

The unique markers served a second function, the AR system uses the markers as reference points to overlay the mesh. As the user moves around the panel the mesh automatically reorients itself. This can be viewed in an online video on YouTube (Spicer, 2018). The panels and the markers can be clearly seen in Figure 1. Within the Hololens environment a user would see a large white polygon, which is the visualization of the structural data in mesh form (Fig. 5); the blue peak on that polygon is a structural anomaly. Beneath the mesh, for the benefit of the reader, the panel has been outlined and the small polygon is where the unique identification marker is located. Even in the dark environment in which this the assembly took place the marker identification and position system worked remarkably well.

\subsection{Analysis}

The analysis will be discussed under three themes (1) problematics of automation (2) the need for co-production and (3) what a platform economy means in this context. First the research supports the supposition that it is problematic to automate everything. Recent reports of Tesla removing robots from their factory and replacing them with people add increased support to this position (Maynard, 2014; Gibbs, 2018). When assembling the igloo, the researchers intervened regularly, mainly because certain tasks required judgment or improvisation. It was more efficient to do tasks like applying jointing glue manually. This resulted in users' hands getting dirty, but this did not inhibit their ability to call and overlay data using the Hololens gesture interface.

In parallel, the robotic assisted assembly, was helpful where time was required to make a judgment call. The robots could be paused, holding the panel in its precise position while a problem was discussed, or data was called up in the Hololens and overlaid on the panel in real time. Due to time constraints it was not possible to test this system with industry users to assess benefits and legibility of data. However, this will be an important aspect to study in the next phase of research.

The second theme that emerged, related to the first, was co-production. The researchers and the robot were working together to assemble the structure. Each doing things that the other were not easily capable of. Framed like this, in any given process, it will be likely people will need hands free to control additional machinery. In this respect it becomes important to analyze and understand the processes and roles of construction in terms of the extent to which their characteristics involve repetition or improvisation. This will help future research target meaningful areas for automation.

The third theme returns to the title of the paper and asks about the possibility of a platform economy for construction. Uber and AirBnB have disrupted very specific markets, they are markets that have only one specific service. Construction, by contrast comprises many dozens or hundreds of services and suppliers to make a single building. So an 'Uber for construction' is unlikely in the near future. The research documented here demonstrates that specific aspects can be automated, and a platform created for what we might term 'micro-services' within the larger process of construction. It demonstrates what is potentially achievable in the short term is the creation of specific micro-platforms servicing specific niches within the wider construction ecosystem.

\section{CONCLUSIONS AND FUTURE WORK}

Arguably the beginning of the twenty-first century has been defined by the emergence of powerful platform economies such as Amazon, Uber and AirBnB. The infrastructures that support and potentially expand the research of these economic models also continues to expand. The Internet of Things (IoT) creates the possibilities of connections between physical devices while blockchain and Bitcoin create a raft of possibilities from smart 
contracts to decentralized models for moving and validating currency and value.

There are strong similarities between Uber, AirBnB and modern construction. They are all distributed networks of services and assets. They all, typically, do not own core assets for their business; AirBnB does not directly own accommodation rented on its platform and large building contractors rarely own the cranes or vehicles that do they majority of the construction work. Uber legally defines its drivers as 'partners' not employees and main Building Contractors sub-contract most of the building work to others. Although construction is a more complex network of services than the focus of our previous examples, this research aims to argue that organizationally the construction sector has much in common with other sectors that have already been disrupted by platform economies. Yet digital platforms are not common place in construction. However, they are beginning to be used in areas surrounding construction. They are being used to optimize design (Anderson et al., 2018), for building management and the co-working space provider 'wework' are using platforms effectively for managing building occupancy. Through the digital igloo technology demonstrator, this research aims to show how specific aspects of design and construction might be streamlined through digital platforms. This raises the questions what aspects? It is likely that aspects of construction that exhibit similar characteristics to existing platform economies will be the first to change. The transportation of materials to, from or between sites has parallels with Uber and connecting people or sites with physical assets for set periods of time (such as cranes and equipment) could be seen as similar to AirBnB. There is a need for further research into detailed aspects of construction process to identify aspects that might benefit from the 'platform economy' concept.

With specific regard to the research project conducted and documented here, the process revealed a number of areas that require further investigation. Firstly, in the same way we automatically recognized the position of the robot-it is also necessary to implement technology to accurately locate the build platform. This project used a plywood ring to fix the igloo in place (Fig. 1), the ring was manually measured and positioned. A small rotational error of approximately 3 degrees was not apparent as the first and second panel were fixed because it was visually insignificant. However, as the third and fourth base panel were positioned the rotational problem became obvious as the panels were not aligning with the base. Although the base was repositioned correctly, the panels already fixed were now out of position; this caused ongoing issues as the assembly progressed. A valuable piece of additional research would be automatic recognition of fixed objects in space to which the assembly must relate. A second area for future work would be simulating the assembly process. This innovation, potentially using the HoloLens, would also help identify any anomalies in the positioning and calibration of the system.

Within the context of construction, deviations and errors or 1-2 millimeters or degrees are acceptable. Within the context of automation, it is not. As these errors compound and result in inaccuracy that calls into question the claimed precision and quality benefits of automation. Thus, this presents cultural issues for construction to change what is and is not deemed acceptable. Certainly with robotics and AR our expectations are often informed by both science fiction and with cutting edge research. Recent reports of robots building IKEA furniture (Crane, 2018), and robotic promotional videos from Institute of Computational Design and Construction Stuttgart make robotic assembly look effortless (Jessica Mairs, 2016). However, this promotional material do not necessarily fully convey the complexity, diversity and man-hours of the teams that bring these robotic concepts into reality. The aim of this research was to deepen our understanding of the opportunities and obstacles for robotics and AR in an automated construction environment.

Key take-aways from this research include:

1. Construction is organisationally very similar to many sectors being disrupted.

2. Many aspects of simple design, fabrication and assembly could be contained within a platform.

3. Construction has a more complex structure than sectors being disrupted which makes direct application challenging.

4. Sub-services within construction may be susceptible to a platform economy.

5. The main cause of disruption in other sectors is a belief it is immune to a particular phenomenon. The biggest hurdle for the construction sector in this regard is likely to be cultural rather than technical. There would need to be a cultural change to embrace research, innovation and the potential of new technology.

In summary although the technology demonstrator proved proof-of-concept it brought several other factors to center stage. Firstly, at every stage of set up there were potential deviations that added small calibration errors. 
Although these were small, perhaps a 1-2 mm deviation or 3-degree rotation deviation. These compounded each other resulting in unacceptable error during construction. The room in which this build took place also suffers from significant solar gain at key points of the day. Temperature is known to affect the Optitrack capture data but to what extent it influenced accuracy is not known. Secondly, not everything could be automated and the degree to which a task or role requires judgement or improvisation related directly to how simple or complex it is to automate that process. Immediate future opportunities for robotics are then most likely to succeed within processes and practices where there is some-but limited-judgement or personalization required. The Augmented Reality aspect of the research also suggests potential in displaying and combining disparate information. However, some mutual understanding of the data and objects from the disparate domains is critical for the data to be useful in specialist contexts such as these.

\section{ACKNOWLEDGEMENTS}

The author would like to thank the many researchers and specialists that made this project possible. University of Auckland Research Unit: Jack Guo on Augmented Reality and HoloLens programming; Cameron Spicer on robotics and automated assembly; Xi Shao for early work on the robotic and parametric proof-of-concept. UNITEC Unit: Yusef Patel and Annaliese Milus on digital fabrication. Centre for Advanced Composite Materials: Composite specialist and Researcher Mark Battley. The author would also like to thank Chris Speed who provoked some of the themes discussed in this paper.

\section{REFERENCES}

Amor, R. et al. (2012) 'Snagging: An Investigation of Location-based Services', in Proceedings of CIB W87. Beirut, Lebanon, pp. 59-68.

Anderson, C. et al. (2018) 'Augmented space planning: Using procedural generation to automate desk layouts', International Journal of Architectural Computing, 16(2), pp. 164-177. doi: 10.1177/1478077118778586.

Barton, C. (2014) The Battle of Glen Innes, Noted. Available at: https://www.noted.co.nz/money/property/thebattle-of-glen-innes/ (Accessed: 29 May 2018).

Bock, T. and Linner, T. (2009) 'Automation and Robotics in On-site Production and Urban Mining, New Perspective in Industrialization in Construction-A State-of-the-Art Report, Eds: G', Grimscheid, F. Scheublin, CIB-Publication.

Bossink, B. A. G. and Brouwers, H. J. H. (1996) 'Construction waste: quantification and source evaluation', Journal of construction engineering and management. American Society of Civil Engineers, 122(1), pp. 55-60.

Braumann, J. and Brell-Cokan, S. (2013) Rob | Arch 2012: Robotic fabrication in Architecture, Art and Design. Wien: Springer/Verlag.

Bresnen, M. and Marshall, N. (2000) 'Partnering in construction: a critical review of issues, problems and dilemmas', Construction Management and Economics, 18(2), pp. 229-237.

Burry, M., Burry, J. and Davis, D. (2011) 'Untangling Parametric Schemata: Enhancing Collaboration through Modular Programming', in Leclercq, P., Heylighen, A., and martin, G. (eds) CAAD Futures 2011: Designing together. Liège, Beligum: Les Editions de l'Université de Liège.

Carpo, M. et al. (2007) Leon Battista Alberti's Delineation of the City of Rome (Descriptio Vrbis Romce). Arizona Center for Medieval and Renaissance Studies (ACMRS).

Carpo, M. (2011) 'The Alphabet and the Algorithm'. Cambridge, Massachusetts: The MIT Press.

Chalhoub, J. and Ayer, S. K. (2018) 'Performance effects of using mixed reality for electrical point layout tasks', in Amor, R. and Dimyadi, J. (eds) Evolving Construction: Towards a technological revolution Proceedings of the 18 the International Conference on Construction Applications of Virtual Reality. Auckland: The university of Auckland, pp. 103-110.

Crane, L. (2018) Watch robots assemble a flat-pack IKEA chair in just 9 minutes Read more: 
https://www.newscientist.com/article/2166741-watch-robots-assemble-a-flat-pack-ikea-chair-in-just-9minutes/\#ixzz5yUwKtXRt, New Scientist. Available at: https://www.newscientist.com/article/2166741watch-robots-assemble-a-flat-pack-ikea-chair-in-just-9-minutes/.

Egan, S. J. (1998) Rethinking Construction: The Report of the Construction Task Force. London: Department of Trade and Industry.

Gibbs, S. (2018) Elon Musk drafts in humans after robots slow down Tesla Model 3 production, The Guardian.

Glöss, M., McGregor, M. and Brown, B. (2016) 'Designing for labour: uber and the on-demand mobile workforce', in Proceedings of the 2016 CHI conference on human factors in computing systems. ACM, pp. 16321643.

Gordon, R. (2015) State-led gentrification and impacts on residents and community in Glen Innes, Auckland. University of Auckland.

Graham, S. (2002) 'CCTV: The stealthy emergence of a fifth utility?', Planning Theory \& Practice. Taylor \& Francis, 3(2), pp. 237-241.

Hale, J. R. (1994) The Civilization of Europe in the Renaissance. Fontana Press. Available at: https://books.google.co.nz/books?id=QStqQgAACAAJ.

Hill, C. (2001) 'Latham's legacy', Building, (50). Available at: http://www.building.co.uk/story.asp?storyCode=1014461.

Hinze, J. and Tracey, A. (1994) 'The contractor-subcontractor relationship: the subcontractor's view', Journal of Construction Engineering and Management. American Society of Civil Engineers, 120(2), pp. 274-287.

Jessica Mairs (2016) ICD/ITKE Research Pavilion 2015-16: Video, Dezeen. Available at: https://www.dezeen.com/2016/05/05/robotically-fabricated-pavilion-university-of-stuttgart-studentsplywood-icd-itke/ (Accessed: 3 September 2019).

Kumaraswamy, M. M. and Matthews, J. D. (2000) 'Improved subcontractor selection employing partnering principles', Journal of management in engineering. American Society of Civil Engineers, 16(3), pp. 4757.

Latham, S. M. (1994) Constructing the team: final report. London: H.M.S.O.

Massey, D. (1994) Space, place, and gender. Edited by I. ebrary. Minneapolis: University of Minnesota Press.

Maynard, M. (2014) ‘Tesla’s Elon Musk: Take Our Patents, They’re Yours', Forbes.

McEwen, I. (2003) Vitruvius: writing the body of architecture. London, England: The MIT Press.

McLeod, M. (1983) “'Architecture or Revolution”: Taylorism, Technocracy, and Social Change', Art journal. Taylor \& Francis, 43(2), pp. 132-147.

McMeel, D. (2009) The Artistry of Construction, Architecture. Edinburgh University.

McMeel, D. and Amor, R. (2012) 'Digital Ecologies: A shifting paradigm for construction', in Lin, Y.-C. and Kang, S.-C. J. (eds) Proceedings of ConVR 12th International Conference on Construction Applications of Virtual Reality. Taipei, Taiwan: National Taiwan University Press, pp. 460-466.

McMeel, D. and Amor, R. (2013) 'Ecosystem Information Models: Visualising complex data to support collaborative decision-making', in Proceedings of 13th International Conference on Construction Applications of Virtual Reality. London, England.

McMeel, D. and Coyne, R. (2004) 'Dirty Work', in Chamberlain, A., Fiore, S., and Knight, J. (eds) 18th British HCI Group Annual Conference: Designer, User, Meaning Maker: Rethinking Relationships for a more Creative HCI. Leeds Metropolitan University.

McMeel, D., Coyne, R. and Lee, J. (2005) 'Talking Dirty: Formal and Informal Communication in Construction Projects', in Martens, B. and Brown, A. (eds) CAADFutures: Learning from the Past. Vienna: Österreichischer Kunst- und Kulturverlag, pp. 265-274. 
McMeel, D. and Sweet, K. (2016) Roadmap for supporting innovation in the New Zealand Construction Sector. Wellington. Available at: http://www.branz.co.nz/cms_show_download.php?id=c8262629abcbcec9b62161bca93a9296afe431d6.

Menges, A. (2012) 'Material computation: Higher integration in morphogenetic design', Architectural Design. Wiley Online Library, 82(2), pp. 14-21.

Peansupap, D. V. and Walker, P. D. H. T. (2005) 'Factors Enabling Information and Communication Technology Diffusion and Actual Implementation in Construction Organisations', ITCon, 10, pp. 193-218.

Pearson, C. and Delatte, N. (2005) 'Ronan point apartment tower collapse and its effect on building codes', Journal of Performance of Constructed Facilities. American Society of Civil Engineers, 19(2), pp. 172-177.

Pollio, V. and Morgan, M. H. (1960) The Ten Books of Architecture. New York: Dover Publications, Inc.

Priestley, L. (2015) Residents fight eviction in Glen Innes, Stuff. Available at: https://www.stuff.co.nz/auckland/local-news/east-bays-courier/66089769/residents-fight-eviction-inglen-innes (Accessed: 29 May 2018).

Romm, T. (2015) 'Round 1 goes to the lobbyists', Politico, 29 June. Available at: http://www.politico.com/agenda/story/2015/06/internet-of-things-government-lobbying-000097.

Ruddock, L. (2006) 'ICT in the construction sector: computing the economic benefits', International Journal of Strategic Property Management, 10, pp. 39-50.

Schön, D. (1979) 'Generative metaphor: a perspective on problem-setting in social policy', in Ortony, A. (ed.) Metaphor and thought. Cambridge: Cambridge University Press.

Speed, C. and Oberlander, J. (2016) 'Designing from, with and by Data: Introducing the ablative framework', in Future-Focused Thinking. Brighton.

Spicer, C. (2018) The Digital Igloo - Augmented Reality // Automated Robotic Fabrication, YouTube. Available at: https://youtu.be/GpnkNORIP9M (Accessed: 19 February 2019).

Sulankivi, K. et al. (2010) '4D-BIM for construction safety planning', in Proceedings of W099-Special Track 18th CIB World Building Congress, pp. 117-128.

Thrift, N. (2005) Knowing capitalism. London: SAGE Publications 2005.

Wang, X. and Dunston, P. S. (2007) 'Design, strategies, and issues towards an augmented reality-based construction training platform', Journal of information technology in construction (ITcon). Citeseer, 12(25), pp. 363-380. 